\title{
FARINOGRAPHIC PARAMETER VARIATION OF DOUGHS FROM WHEAT FLOUR WITH AMOUNT OF WATER ADDED
}

\author{
Gheorghe Voicu ${ }^{1}$, Gheorghe Constantin ${ }^{2}$, George Ipate ${ }^{1}$, Paula Tudor ${ }^{1}$ \\ ${ }^{1}$ University "Politehnica" of Bucharest, Romania; ${ }^{2}$ High School "Nicolae Iorga" Nehoiu, Romania \\ gheorghe.voicu@upb.ro
}

\begin{abstract}
In this paper we present the rheological properties of dough made from wheat flour FA-480 (0.44$0.48 \%$ ash content) and water in different proportions relative to the flour used (from $55 \%$ to $65 \%$ in increments of $2.5 \%$ ) according to the experimental research. The moisture content of flour was 11.7-12.0\%. Measurements were made in laboratory conditions, using an electronic Brabender Farinograph (according to methods AACC 54-21.01 and AACC 54-50.01), and a kneader with a planetary spiral arm equipped with torque transducer and a proper strain gauge. For five types of dough characteristics the data of the obtained farinograph curves and shape parameters for variation curves or torque shaft were analyzed. It was observed that with increasing the amounts of added water content for both equipments dough fell, and the values given for dough prepared with the planetary stirrer are lower compared than that prepared by the Brabender farinograph. Simultaneously, in the paper other farinographic parameters obtained in our experiments are presented.
\end{abstract}

Keywords: wheat flour, water added, dough mixer, farinographic characteristics, flour quality.

\section{Introduction}

There are cases where the technological process of baking flour destined not have the necessary technological characteristics conversion into finished products of appropriate quality for both natural causes and not due to storage conditions established as norms, [1-4]. These discrepancies can be remedied in both wheat mills and bread factories by adding additives and ingredients to compensate for lower qualities of wheat or flour.

But there are cases when, on the technological flow, improperly used information provided by the laboratories of the respective factories is misinterpreted. This information refers to the ability of hydration (or absorption) of water to flour in question, [2;3;5].

Flour hydration ability or capacity to retain water is an important property that determines the yield flour dough. Flour, which absorbs more than $60 \%$ water, gives a slow fermenting dough and therefore maintains its shape well during the final fermentation and baking. From flour, which absorbs

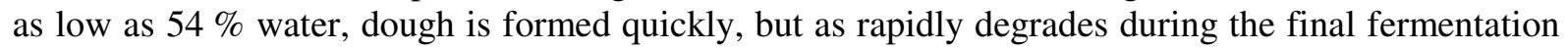
and the finished product emerges widened, [3-7].

Flour hydration ability is equivalent to the amount of water that is added to one hundred kilograms of flour (14\% moisture) to obtain fermented dough of a specific consistency in certain wellestablished working conditions, [3,5,6,7].

The hydration ability of flours has values varyimg according to the assortment of flour: flour consumer $-c h=58-64 \%$; for semi-milled flour $-c h=54-58 \%$; for white flour $-c h=50-55 \%$. It is a property that influences the yield of technological flour in the dough and in the finished products, the ability to form and retain gases during preparation of the dough, the mechanical properties of dough made from a particular type of flour, [7-10]. The flour particle size influences the capacity of its hydration, the rheological characteristics of gluten and dough, amylolitic enzyme activity on the uptake of bread.

It is known, both in theory and especially in practice every day, that adding a larger amount of water relative to flour in the bowl mixer the dough obtained is soft and sticky, with adhesion to the higher side of the tank, so that it will come off harder. Meanwhile, the dough with a moisture content lower than the absorbency of the flour will be harder kneaded and worked in the technological flow production, [7; 9].

This paper proposes emphasizing behavior of kneading wheat flour, depending on the content of water added (in percentage from $55 \%$ to $65 \%$ compared to flour in steps of $2.5 \%$ ) by tests using the farinograph Brabender and as a kneader usual pastry Dito Sama BE5 equipped with a torque transducer shaft drive and data acquisition system. The purpose of comparative experiments is to demonstrate that the rheological, or farinographic, parameters of wheat doughs can also be determined 
directly on any type of kneader if it is adequately equipped as our kneader. Equivalence coefficients between the two measurement systems can be introduced.

\section{Materials and methods}

Methodology experiments using the farinograph Brabender apply the method AACC 54-21.01 [7] of dough rheologic experiments and the method AACC 54-50.01 to determine the absorption capacity of the flour and the instructions in the technical manual of the machine. White wheat flour used was FA-480, with an ash content of about $0.44-0.48 \%$ of the mill Spicul S.A. Vedas, Romania, in 2010 wheat production in southern Romania. The moisture content was determined within the limits of 9.86-11.20\%. Temperature of the flour used was $24-25^{\circ} \mathrm{C}$ (ambient laboratory), and the water temperature was $32 \pm 2{ }^{\circ} \mathrm{C}$ (water is heated and maintained at a constant temperature in a thermostatically controlled water bath).

In the case of the planetary mixer Dito Sama BE5 the dough was kneaded for 11 minutes (more than the real kneading of bread dough in such a kneader) and the speed arm spiral was set at the same value as that of the Brabender farinograph arms, i.e. $60-62 \mathrm{rpm}$, but the drive wheel speed was slightly higher due to the actuation mechanism hypocycloidal (about $110 \mathrm{rpm}$ ). For the time specified there were torque variation curves obtained (after processing in LabView program), which are interpreted by the computer software. The quantities of distilled water added were the same for both devices: $55 \% ; 57.5 \% ; 60 \% ; 62.5 \% ; 65 \%$ to wheat flour. A quantity of flour $1 \mathrm{~kg}$ was used.

\section{Results and discussion}

The farinograph curves obtained by the experiments with the Brabender farinograph for the mentioned doughs are shown in Fig. 1, and the torque variation curves ofthe mixer Dito Sama shaft BE5 in Fig. 2.

From the farinograph curves the values of the farinograph parameters have been extracted (characterizing the rheology of dough formed) for the time development of the dough DA (min), stability $S$ ( $\mathrm{min}$ ), degree of softening $D S$ (FU), consistency (normal) $N C$ (FU) the absorption capacity of the flour (Brabender farinograph required) $W A(\%)$ elasticity $E(\mathrm{FU})$, the farinograph index of the dough $F Q N$, and the values of these parameters are shown in Table 1.

Table 1

Farinograph parameter variation of dough with the amount of water added to kneading

\begin{tabular}{|c|c|c|c|c|c|c|c|c|c|c|}
\hline \multirow[b]{2}{*}{ Rheological characteristic } & \multicolumn{5}{|c|}{ At Brabender farinograph } & \multicolumn{5}{|c|}{ At Dito Sama BE5 mixer* } \\
\hline & $\begin{array}{l}55 \% \\
\text { water }\end{array}$ & \begin{tabular}{|c|}
$57.5 \%$ \\
water
\end{tabular} & $\begin{array}{l}60 \% \\
\text { water }\end{array}$ & $\begin{array}{c}62.5 \% \\
\text { water }\end{array}$ & $\begin{array}{l}65 \% \\
\text { water }\end{array}$ & $\begin{array}{l}55 \% \\
\text { water }\end{array}$ & $\begin{array}{c}57.5 \% \\
\text { water }\end{array}$ & $\begin{array}{l}60 \% \\
\text { water }\end{array}$ & $\begin{array}{c}62.5 \% \\
\text { water }\end{array}$ & $\begin{array}{l}65 \% \\
\text { water }\end{array}$ \\
\hline Development Time, min & 1.9 & 1.8 & 1.8 & 1.7 & 2.3 & 0.8 & 1.4 & 1.4 & 0.7 & 1.2 \\
\hline Stability Time, $\min$ & 2.3 & 1.9 & 1.3 & 1.3 & 1.3 & 1.3 & 2.5 & 2.4 & 1.4 & 1.4 \\
\hline Degree of softening, FU & 125 & 148 & 136 & 116 & 79 & 16 & 54 & 19 & 40 & 33 \\
\hline $\begin{array}{l}\text { Degree of softening, ICC } \\
\text { method ( } 12 \text { min after peak) }\end{array}$ & 134 & 160 & 157 & 134 & 91 & - & - & - & - & - \\
\hline Farinographic index $F Q N$ & 25 & 24 & 25 & 25 & 36 & - & - & - & - & - \\
\hline Consistency (normal) $C N, \mathrm{FU}$ & 795 & 703 & 622 & 548 & 452 & 556 & 571 & 552 & 367 & 290 \\
\hline Moment peak, FU & 928 & 805 & 682 & 598 & 477 & 593 & 593 & 578 & 384 & 323 \\
\hline Water added, $\%$ & 55.0 & 57.5 & 60.0 & 62.5 & 65.0 & 55.0 & 57.5 & 60.0 & 62.5 & 65.0 \\
\hline $\begin{array}{l}\text { Water absorption (corrected } \\
\text { for } 500 \mathrm{FU} \text { ) }\end{array}$ & 62.5 & 62.6 & 63.1 & 63.1 & 62.9 & - & - & - & - & - \\
\hline Elasticity, FU (after $10 \mathrm{~min}$ ) & 82 & 57 & 47 & 39 & 27 & 57 & 40 & 33 & 37 & 41 \\
\hline Consistency coefficient $k_{f}$ & 0.86 & 0.87 & 0.91 & 0.92 & 0.95 & 0.94 & 0.96 & 0.96 & 0.95 & 0.90 \\
\hline \multicolumn{6}{|c|}{ Equivalence coefficient $k=k_{\text {mixer }} / k_{\text {farinograph }}$} & 1.093 & 1.103 & 1.054 & 1.032 & 0.947 \\
\hline
\end{tabular}

* Because of the curve unevenness the values shown are approximate 

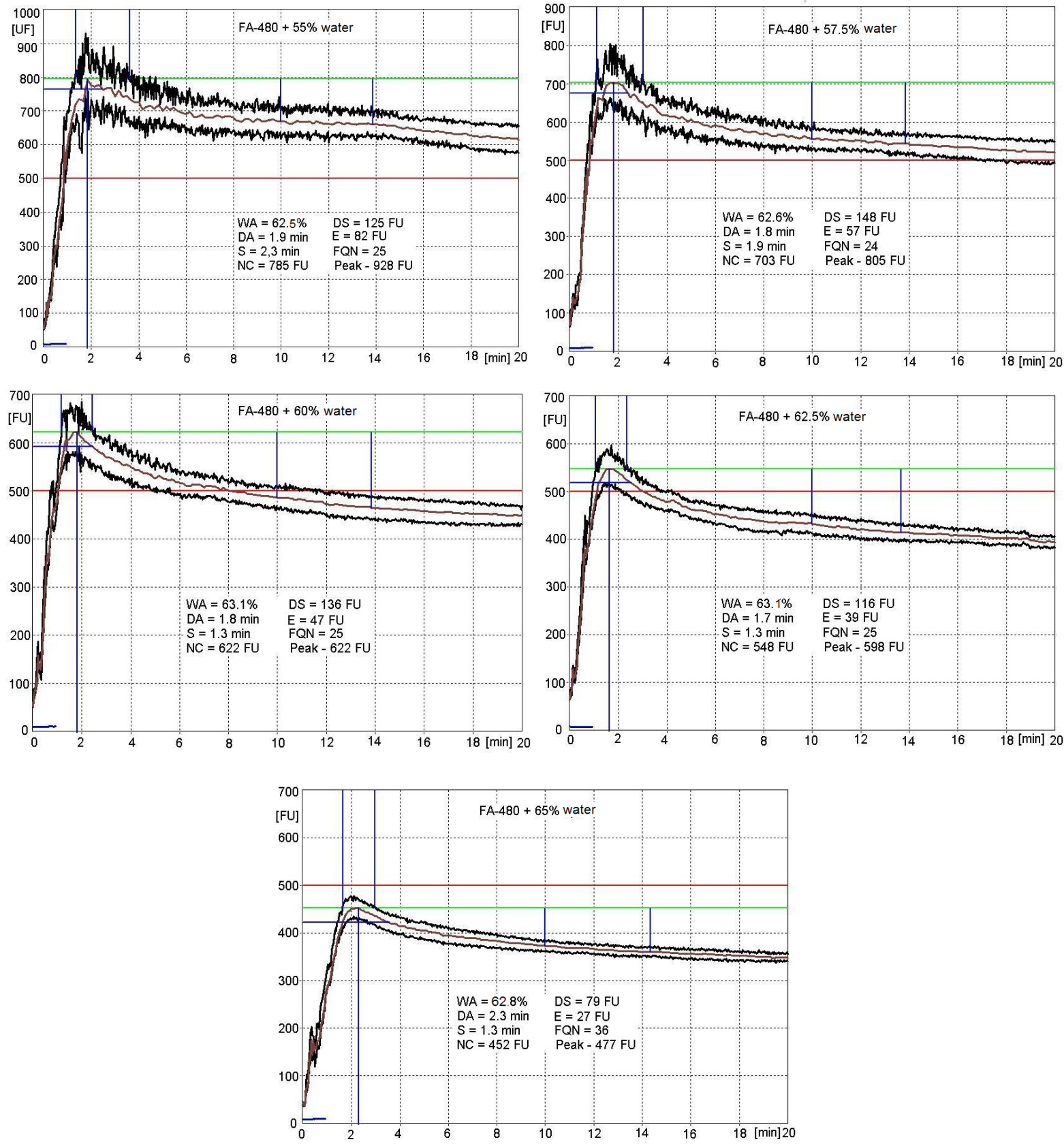

Fig. 1. Farinograph curves obtained from the experimental farinograph Brabender for different water contents added

For proper hydration of flour, corrections were made in the related apparatus for estimating and proper interpretation of other parameters, but mainly we watched the behavior of dough with different amounts of water added.

Also, the degree of softening of dough is shown in the farinograph curves in Table 1 for 10 minutes while the kneading time was 12 minutes (according to the method ICC, [11]).

The experimental stand (with Dito Sama kneader BE5) curves of the torque shaft kneading arm are set similarly to those in the farinograph Brabender (where $1 \mathrm{UF}=0.01 \mathrm{~N} \cdot \mathrm{m}$ ).

From the analysis of the farinograph curves obtained at the farinograph Brabender, it appears that during the development dough has a slightly decreasing trend with the increase in the amount of water added until a percentage of water approximately equal to the capacity of moisture, but immediately after the development time the increase is significant. So, if at first because of added water percentage 
from $55 \%$ to $62.5 \%$, dough development times require 1.9-1.7 minutes at a rate of $65 \%$ added water (over hydration capacity of the flour that is $62.9 \%$ ), the development time increases to $2.3 \mathrm{~min}$.
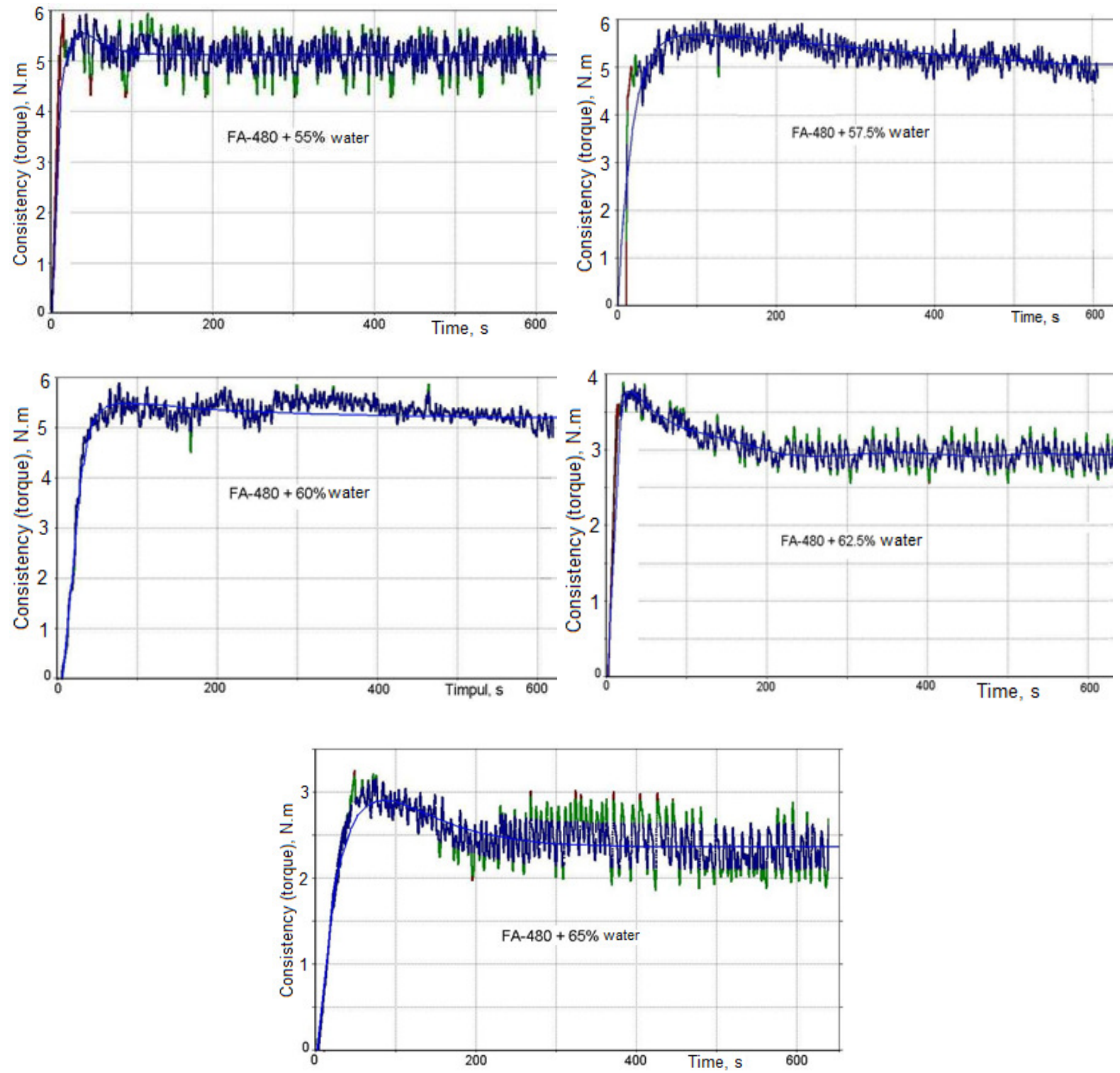

Fig. 2. Farinograph curves obtained from experimental measurements with Dito Sama kneader BE5 for various water contents added

On the stand the experimental development time is relatively uniform, hydration particles of flour and form of the dough taking place in a relatively short time in all experimental samples, a slight deviation from doughs containing added water by $55 \%$, or $62.5 \%$, at which the dough formation and development took place very quickly (about $0.7-0.8 \mathrm{~min}$ ), the other samples during the development of the dough are within 1.2-1.4 min.

Concerning the stability of the dough during the kneading process it significantly reduces the dough with added water by $55 \%$ compared to the dough with water in a ratio of $60 \%$ (from 2.3 minutes to 1.3 minutes), after which it remains at the same level (1.3 min dough with $60-65 \%$ of water added to kneading) to the samples tested by the Brabender farinograph. At the planetary mixer, dough stability has values about the same size (about 1.3-1.4 min), with significant deviations in addition to evidence by $57.5 \%$ and $60 \%$ added water $(2.4-2.5 \mathrm{~min})$ even if these values are not very high.

With regard to the degree of softening, it is an increasing trend of percentage of added water of $55 \%$ (which has a value of $125 \mathrm{uF}$ ), to $57.5 \%$ added water (when the value of $148 \mathrm{uF}$ ), followed by a trend decreasing to increasing the percentage of added water, decreasing the amount of UF 79, $65 \%$ 
added water. So the dough, although falls below normal consistency, kept at higher values of consistency, with increasing amounts of water added to kneading. If the farinograph Brabender values degree of softening of the dough are relatively high (measured in units by the farinograph, UF) for doughs prepared with the planetary kneader Dito Sama BE5 it has values of 3-4 times smaller, in the range 16-54 UF, with a sinusoidal variation. Doughs with $57.5 \%$ added water (the degree of softening was 54 UF) and dough with $62.5 \%$ added water (where the consistency of the dough decreased about 40 UF) have the values of the larger degree of softening in the experimental stand.

Related to dough consistency, it must be specified that its value is correlated with the amount of water added, hovering around $500 \mathrm{UF}$, to the dough prepared at the farinograph Brabender, with water added about the ability of hydration of the flour (about $62.5 \%$ ). It may be noted that the dough consistency value decreases with increasing the water content added for both devices, but the values (units, the farinograph FU) presented that the doughs prepared with the planetary mixer are lower compared to those prepared with the farinograph.

In terms of quality flour measured by the index of the farinograph FQN (analysis of the farinograph curves and aggregated data presented in Table 1) it notes that it remains roughly constant with increasing the amount of added water from $55 \%$ to $62.5 \%$ (around FQN value $=25$ ), increasing the value $\mathrm{FQN}=36$ to $65 \%$ of dough with water added to flour.

Measuring directly on the chart printed bandwidth to 10 minutes after the start of kneading, both at the farinograph Brabender and at the planetary mixer the elasticity of the dough could be estimated, in the farinograph units, its values are presented in Table 1.

It appears that the elasticity decreases with increasing the water added to kneading, rising from 82 UF $55 \%$ added water to 27 UF for dough with $65 \%$ water, the doughs prepared with the farinograph, in contrast to the doughs prepared with the planetary kneader have elasticity of a minimum value (about $33 \mathrm{UF)}$ to $60 \%$ water added to the dough, and then increases with increasing the quantity of water at about $41 \mathrm{uF}, 65 \%$ to the dough with added water.

Analyzing the graphs in Figure 1, there is strong similarity of timing variation of the resistant shaft kneader planetary profile with the farinograph curves shown in Figure 2. The width of the band variation of the consistency of the dough gives more constant curves of the traced farinograph Brabender, instead these are outlined based on the data acquired from the experimental stand with kneader planetary show jumps, we believe, because the arm kneading spiral has planetary motion and the area of kneading inside the tub is different from the cross-sectional area of the tank, and that the dough moved by rotation differs from others. It is noted that the bandwidth consistency is higher in dough with $65 \%$ added water, prepared in the planetary kneader parts for dough with the same percentage of added water, but prepared with the farinograph Brabender bandwidth (elastic dough) is smaller.

Values could not be estimated as the index of the flour FQN to the planetary mixer, as there is no method of reading its graphs drawn.

Also the tendency has been found to decrease the degree of softening of the dough by the amount of water added, and the elasticity thereof, the doughs prepared with the random deviations of the planetary arm kneader spiral.

It can also be stated that as the amount of water added to kneading increases, the dough elasticity decreases in doughs prepared with the farinograph and it shows a minimum of variation in doughs prepared with the planetary kneader equipped with the arm spiral in doughs with $60 \%$ water added.

\section{Conclusions}

1. Determination of kneading dough moment resistance variation of wheat flour with different amounts of water added through two different ways using the Brabender farinograph electronic and experimental stand with the help of a planetary kneader Dito Sama BE5 showed the same allure variation curves with slight deviations from one machine to another.

2. We found a trend of changing the physical characteristics of dough with the amount of water added (flour FA-480 with 9.85-11.2\% humidity).

3. At low contents of added water (i.e. $55 \%$ for flour type FA-480) and at low speeds arm kneading the dough detaches easily from the side of the tank, compared to the cases where the water 
content increases (most evident $65 \%$ water is added), the dough remains trapped on the walls of the tank without being drawn up to the end of the kneading process (about 10 minutes).

4. It has been noticed that by increasing the kneading rate of about two times, even at higher added water contents ( $65 \%$ of the flour), the dough decays relatively quickly from the walls of the tamk after the dough has been developed and formed low speed of kneading arm.

5. In the terms of the dough consistency (as the average / normal recorded on both devices, after the development and formation of the dough composition and the peak of the curve) there is the decreasing trend.

6. It has been demonstrated that there is sufficient similarity between the two appliances irrespective of the amount of added water and proper equipping of any mixer in the bread factories can lead to the determination of the rheological parameters of doughs in order to establish the optimal parameters of the working regime of the equipment processing the dough. It is also evident from the approximate values of the consistency coefficients and equivalence coefficients between the devices.

\section{References}

1. Linina A., Ruza A., Kunkulberga D., Rakcejeva T. The influence of environmental conditions on winter wheat whole meal protein content and rheological properties. 9th Baltic Conference on Food Science and Technology "Food for Consumer Well-Being" FOODBALT 2014 Conference Proceedings. LLU, 2014, Jelgava, Latvia, pp. 66-71.

2. Constantin G., Voicu Gh., Marcu S., Carp-Ciocardia C. Theoretical and experimental aspects regarding the rheological characterization of behaviour of some Romanian wheat flours with Chopin Alveograph. Actual tasks on agricultural engineering, Opatija, Croatia, vol.39, 2011, pp. 437-448.

3. Masauskiene A., Ceseviciene J. Variation in winter wheat grain qualities as affected by NK fertilisation and grain storage period. II. Dough mixing properties by Brabender Farinograph. Proceedings of the Latvia University of Agriculture, 2006, Vol. 16 (311), pp. 59-67.

4. I. David, The enzyme activity of hemicelullase used on dough obtained from wheat flour, Actual Tasks on Agricultural Engineering, Opatija, Croatia, vol.42, 2014, pp. 353-363.

5. Ipate G., Voicu Gh., Constantin Gh. Simulation of bread dough mixing process with free surfaces using a direct 3D numerical method. Proceedings of the 11th International Congress on Mechanization an Energy in Agriculture, Trakageng 2011, Istanbul, Turkey, 2011, pp. 469-474.

6. Tronsmo K.M., Færgestad E.M., Longva A., Schofield J.D., Magnus E.M. A study of how size distribution of gluten proteins, surface properties of gluten and dough mixing properties relate to baking properties of wheat flours. Journal Cereal Science (35), 2002, pp. 201-214.

7. Method AACC 54-21.01. Farinograph Method for Flour, Methods of the American Association of Cereal Chemists, 10th Edition, 2000, St. Paul, MN.

8. Kalnina S., Rakcejeva T., Kunkulberga D., Rheological properties of whole grain wheat, rye and hull-less barley flour blends for pasta production, Research for Rural Development, 2015, Vol.1, Jelgava, Latvia, pp. 150-156.

9. Muchova Z., Zitny B. New approach to the study of dough mixing processes. Czech Journal of Food Science, Vol. 28(2), 2010, pp. 94-107.

10. Sabovics M., Straumite E. Rheological properties of triticale (Triticosecale wittmack) flour blends dough. Research for Rural Development - International Scientific Conference, Jelgava, Latvia, 2012, vol. 1, pp. 143-148.

11. ICC-Standard No. 115/1. Method for using the Brabender Farinograph, 1992. 